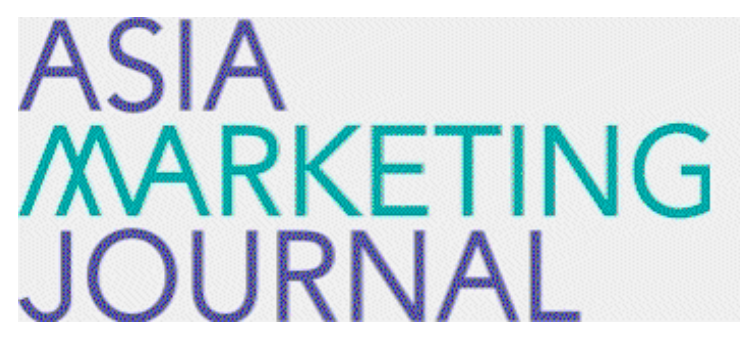

ASIA MARKETING JOURNAL

Volume 3 | Issue 3

Article 4

$9-1-2001$

\title{
인터넷 서비스접점 만족에 관한 연구
}

Sang Kyu Park

Gu Hyun Won

Follow this and additional works at: https://amj.kma.re.kr/journal

Part of the Marketing Commons

\section{Recommended Citation}

Park, Sang Kyu and Won, Gu Hyun (2001) "인터넷 서비스접점 만족에 관한 연 구," Asia Marketing Journal: Vol. 3 : Iss. 3 , Article 4.

Available at: https://doi.org/10.53728/2765-6500.1070

This Article is brought to you for free and open access by Asia Marketing Journal. It has been accepted for inclusion in Asia Marketing Journal by an authorized editor of Asia Marketing Journal. 


\title{
인터넷 서비스접점 만족에 관한 연구*
}

\section{A Study on Internet Service Encounter Satisfaction}

\author{
박상규 (강원대학교 경영 관광 회계학부 교수) \\ skpark@cc.kangwon.ac.kr
}

원구현 (강원대학교 경영 관광 회계학부 강사)

won098@icc.or. $\mathrm{kr}$

서비스 제공자와 고객 상호간에 상호작용의 톡성을 밝히려는 연구는 광범위하게 진행되어
왔지만, 기술 접점(technology interfaces)에서의 고객과의 상호작용에 관한 연구는 다소
적은 편이었다. 본 연구는 이러한 관점에서 기술적 혁신과 진보가 고객-기업 상호작용의 중
요한 요소가 되어가고 있는지를 확인하려고 하였다. 이러한 연구목적을 달성하기 위하여 인
터넷 서비스접점 품질과 고객만족에 미치는 요인들과의 관계를 SPSS 10.0 과 AMOS 4.0 프로
그램을 이용하여 실중분석 하였다.
연구결과 인터넷 서비스접점 경헙을 개선할 수 있는 디지털 기술의 역할을 확인할 수 있었
다. 즉 기업의 웹사이트 이용이 고객에게 보다 나은 가치 있는 편익을 제공에 기여할 수 있
다는 것이다.

* 논문접수: 01.08 게재확정: 02.03 


\section{1. 서 론}

서비스접점(service encounter)은 서비스산업에서만 뿐만 아니라 모든 산업에서 매우 중 요한 요소이다. 이러한 서비스접점은 디지털시대의 급속한 기술의 발전(deployment of technology)으로 인해 전통적인 서비스접점의 성격올 변화시키고 있다. 서비스접점이 전통 적으로 "high-touch, low-tech"로 개념화 되어 왔으나, 디지털 기술들이 이러한 서비스접점 의 성격을 "low-touch, high-tech"로 변화시키고 있다. 이러한 마케텅환경의 변화는 서비스 접점의 관리를 점점 더 어렵게 하는 요소가 되고 있다.

최근 많은 연구들이 서비스접점을 이해하려는 시도를 하고 있지만, 현실적으로 고객들에 게 제공되는 서비스 품질(quality of services)은 개선되어지지 않고 있다. 실질적으로 서 비스 만족(service satisfaction)의 감소로 인해, 미국 고객만족 지수(American Customer Satisfaction Index)가 떨어지고 있는 실정이다(Fornell, Johnson, Anderson, Cha, and Bryant, 1996). 또한 Leaf(1998)는 서비스의 고객 지각(customer perceptions of service) 이 감소하고 있다고 보고 있다. 최근 불량 웹사이트가 그 사이트를 운영하는 기업에 미치는 영향에 관한 Forrester 리서치의 조사에 따르면, 불량 윕사이트로 인해 발생하는 몇 가지 문제점들 중에서 가장 심각한 것은 블량 웹사이트로부터 잠재적 매출이 약 50\%의 손실이 발 생되며, 웹사이트 방문자가 사이트의 첫 방문에서 부정적인 경헙을 했을 때 그 사이트에 되 돌아오지 않을 비율이 40\%을 차지한다는 것이다(Manning, McCarthy, and Souza, 1998). 이 러한 이유 때문에 이 보고서에서는 기업의 평판에 손상올 끼칠 수 있는 사이트룰 폐쇄할 것 을 권고하고 있다.

이러한 경향은 고객이 기업과의 상호작용에서 어떻게 만족하는가와 서비스접점에 대한 이 해가 부족하기 매문이다. 즉 고객을 위해 서비스접점 경헙(service encounter experience) 올 개선하기 위해서 이용되어 질 수 있는 기술의 역할(role of technology)을 이해하지 못 하고 있다는 것이다. 중가하고 있는 디지털 기술의 중요한 역할은 기업과 고객 모두에게 가 치 있는 편익(benefits)을 제공할 수 있다는 것이다(Bitner, Brown, and Meuter, 2000). 그 러나 서비스접점에 대한 이해가 부족하다면, 디지털기술의 활용이 더 큰 부정적 영향을 가 져 올 수 도 있다.

본 연구는 이러한 관점에서 서비스접점의 성격 변화 즉, 대인적 상호작용(interpersonal interactions)과 기술적 상호작용(technology-based interactions)에 대해 고찰하고, 디지 털기술의 효과적인 이용을 통해 서비스접점이 개선되어 질 수 있는가를 실중적 분석을 톻해 확인하고자 한다. 본 연구의 목적은 다음과 같다. 첫째, 인터넷 서비스접점과 고객만족에 영향을 미치는 요인들울 검토하고자 한다. 둘째, 인터넷 서비스접점과 고객만족에 영향을 주는 요인들과의 관계률 실중분석을 통해 검중하고자 한다. 셋째, 실중분석을 뿡해 효율적 인 인터넷 서비스접점 관리와 방향을 모색하고자 한다. 


\section{2. 이론적 배경}

\section{1. 인터넷 서비스접점(Internet Service Encounter)}

Keaveney(1995)는 서비스접점을 '고객과 서비스 종업원과의 인간적 상호작용'으로 정의하 고 있다. 이 정의에서는 서비스접점을 고객과 기업간의 인간적 상호작용으로 제한함으로써 인간관계에 초점을 맞추고 있다. Shostack(1985)는 서비스접점을 '고객과 서비스 제공 기업 과 직접적으로 상호작용하는 기간'으로 정의하고 있다. 이 정의는 일정 기간 동안 고객이 서비스기업과 접촉하는 것, 종업원, 물리적 시설, 기타 유형적 요소 둥을 포합한다. 즉 서 비스접점을 고객과 기업간의 인간적 상호작용으로 제한하지 않고 있다. 또한 Bitner, Brown and Meuter(2000)은 Shostack(1985)과 같이 포괄적인 관점에서 서비스접점을 '고객과 기업 이 상호작용하는 순간'으로 정의하고 있다.

Shostack(1985)은 서비스접점을 분리된 접점(remote service encounter : 비인간적 접촉), 간접적 점점(indirect service encounter : 대면 접촉이 없는 구두를 통한 접촉), 직접적 접촉(direct service encounter : 인간적 접촉)으로 분류하고 있다.

그러나 기존의 대인적 접점(Interpersonal Encounter Relationship)은 인터넷의 발전으로 급격한 변화를 가져오고 있다. 심지어 어떤 경우에는 대면 접촉을 완전히 없애버리기까지 했다. 또한 이러한 기술발달로 인해 기업과의 접촉 희수를 급격히 중가시키기도 한다. 인터 넷으로 인해 전통적인 Marketplace Transaction 이 Market-Space Transaction 으로 전환되고 있다. 특히 더 이상 고객과 기업사이의 물리적인 접촉이 불필요하게 되었다(Rayport and Sviokla, 1995).

인터넷 서비스접점은 서비스 종업원과 고객이 직접 대면하는 전퉁적인 상황이 인터넷으 로 인해 종업원과 고객 사이에 인터넷이라는 매체가 개입되는 상황을 의미한다. 따라서 인 터넷 서비스 접점은 '인터넷 서비스를 통한 소비자와의 직접적인 상호작용(interaction)하 는 기간'으로 정의할 수 있다(Bitner, Brown, and Meuter, 2000). 또한 Bitner, Brown, and Meuter (2000)은 인터넷서비스접점의 증대방법요소를 <그림 1>과 같이 제시하고

$$
\text { <그림 1> 디지털 기술 이용의 이점 }
$$

가능하게 하는 기술 Drivers of Service Encounter Satisfaction

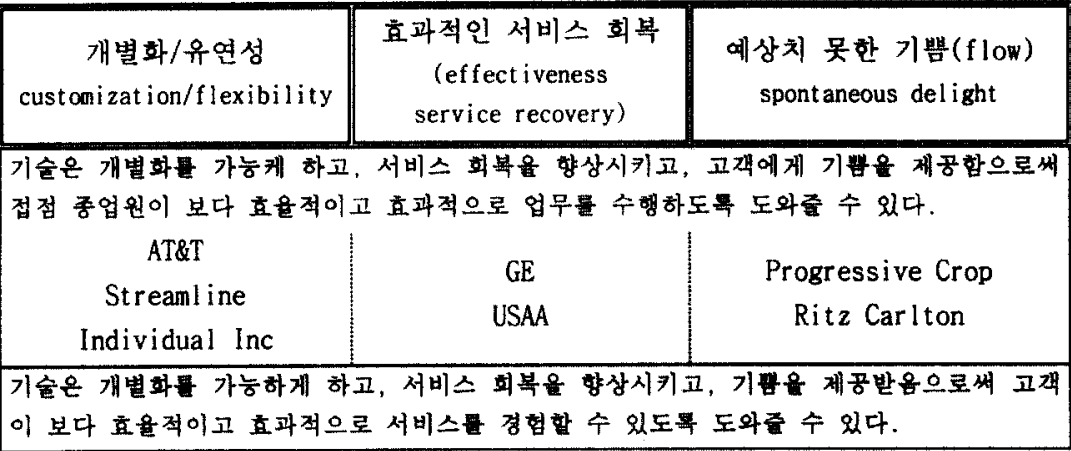




\begin{tabular}{|l|l|l|}
\hline $\begin{array}{l}\text { Amazon.com } \\
\text { Wells Fargo } \\
\text { Federal Express }\end{array}$ & Hartness Int l. & Cisco \\
\hline
\end{tabular}

자료 : Bitner, Mary Jo, Stephen W. Brown and Mat thew L. Meuter(2000), "Technology Infusion in Service Encounter". Journal of Academy of Marketing Science, Vol 28(1), p.142.

\section{2. 개별화(customization)와 유연성(flexibility)}

고객은 서비스접점에서 유연성과 개별화된 서비스가 제공되기를 기대한다(Bettencourt and Gwinner, 1996; Bitner, Booms and Tetrault, 1990; Kelly, 1993). 고객은 엄격한 규칙 을 좋아하지 않는다. 고객은 개인적인 욕구에 맞는 서비스를 원하고 있다(Bitner et al, 2000). 인터넷에서는 이러한 개별화뿐만 아니라 매스커스터마이제이션이 가능하다. Mass Customization 이란 다양하고 개별화된 제품을 평균가격으로 생산하기 위한 유연한 프로세 스와 조직구조를 의미한다. 효율적이고 정교하게 개발된 데이터베이스로 이것이 가능해 지 고 있다(Hart, 1996). 또한 Dabholkar(1996)은 제공되는 서비스에 대한 지각된 퉁제력과 고 객별로 개별화된 서비스의 제공이 기술(인터넷)에 기초한 서비스 품질 평가를 중가시키는 것을 실중적으로 연구하였다. 그리고 Quinn(1996)은 서비스 제공에 있어서 유연성이 인터넷 으로 인해 가눙해진 가장 중요한 품질 개선의 하나라고 주장했다.

이러한 서비스접점 만족을 위한 개별화와 유연성은 여러 연구들에서 언급되어지고 있다. Kelly(1993)는 'discretion'라고 지칭하였고, Surprenant and Solomon(1987)은 'personalization'이라고 지칭하였으며, Bettencourt and Gwinner(1996)온 'adaptation'이 라는 용어로 그 중요성을 언급하고 있다.

\section{3. 서비스회복(service recovery)}

서비스 회복은 서비스 실패(service failure)에 대한 조치로 개념화 할 수 있을 것이다. 즉 서비스 회복은 서비스 실패를 통하여 학습하고 해결한 바툴 뿡하여 고객들의 눈을 통해 기업의 신뢰성을 구축하기 위한 기업의 노력으로 정의 할 수 있다(Hart, Heskett, and Sasser, 1990). 여기서 서비스 실패는 고객들의 기대에 미치지 못하는 상황을 의미하고 있 는데, 서비스 실패는 서비스 전달과정의 어떠한 영역에서도 발생가능성을 내포하고 있는 것 이다.

Bitner, Booms, and Tetreult(1990)는 서비스 실패가 일어난 경우에 서비스 기업이 문제 해결을 위한 적극적인 노력을 기울인 경우에는 오히려 고객들은 긍정적인 태도를 보인다고. 주장하였다. 또한 Blodgett, Hill, and Tax(1997)은 서비스 불평관리의 중요성을 제기하면 서 고객들이 인지하는 서비스 희복노력을 정당성의 논리로 파악하고, 소매서비스를 이용하 는 고객들이 서비스 희복노력을 인지한 후의 서비스 기업에 대한 평가를 실중분석 하였다.

볼만족한 고객이 서비스 실패를 경헙하고 난 다옴의 행동예 대한 이론적인 연구의 바탕을 제공하는 것이 정당성(justice)에 대한 개념으로 볼 수 있다. 공정성(fairness)과 유사한 의미로 할용이 되고 있는 정당성은 사회심리학에 그 기원을 두고 있으며, 다양한 갈둥 상황 에서의 사후 행동을 설명하는데 유용하게 할용되고 있다. 최근의 연구들은 공정성 혹은 정 
당성에 세가지 유형이 있음을 지적하였다. 세가지 유형은 분배 공정성(distributive justice), 절차정당성(procedural justice), 상호작용정당성(interactional justice)이다 (Smith, Bolton and Wagner, 1999; Tax, Brown, and Chandrashekaran, 1998; Oliver and Swan, 1989; Clemmer and Schneider, 1996).

\section{4 예상치 못한 기쁨/플로우(Spontaneous Delight/Flow)}

\subsection{1. 예상치 못한 기쁨}

예상치 못한 기뽐은 고객에게 아주 뛰어난 서비스를 제공하여 다소 놀라게 함으로써 고객 을 기쁘게 만드는 것을 의미한다(Oliver, Rust, and Sajeev, 1997). 이러한 예상치 못한 기 뽐의 제공은 서비스접점 만족의 핵심적인 결정변수가 된다. 고객온 종업원의 즐겁고, 기대 하지 않았던 행동에 직면했을 때, 높은 만족을 느끼는 것으로 나타났다. 톡히 접점에서의 만족을 느낀 고객의 $44 \%$ 가 이러한 이유로 만족한 것으로 나타났다(Bitner et. al, 2000).

기쁨은 만족과는 구분된다. 기쁨은 구매의도와 밀접하게 연관되어 있다. 고객의 기쁨은 만족이나 서비스 품질보다 더 높은 수준의 것으로서 고객애호도를 가져오는 핵심적 변수라 고 할 수 있다(Oliver et. al, 1997). 또한 Oliver et. al.(1997)는 예상치 못한 서비스의 제공에 의해 환기된 기뽐과 긍정적 감정은 기존의 불일치 패러다임에서 형성된 만족에 영향 을 미치며 이로 인한 고객의 유지 즉, 재구매의도에 긍정적인 영향을 미친다는 것을 밝혀냈 다.

\subsection{2. 플로우}

Hoffman 과 $\operatorname{Novak}(1996,2000)$ 은 웹사이트의 반복적인 방문은 풀로우를 용이하게 하는데 달려있다고 제안하면서, 온라인 환경에서 시도되는 성공적인 마케팅 활동은 이러한 플로우 를 충분히 활용할 수 있어야 한다고 주장하고 있다.

이러한 플로우개념은 지난 20 년간의 지속적인 연구에도 불구하고 플로우에 관한 체계적 이고 포괄적인 연구 및 모델화 노력이 부족했던 이유는 플로우를 정확하게 개념화하는 것이 어렵기 때문이다(Nowak, Hoffman, and Yung, 1998).

그러나 지금까지 플로우의 개념을 정의한 여러 연구들을 정리해 보면, '홍분', '즐거움', '기쁨', '재미', '최적의 경험', '몰입상태', '기술과 도전의 균형', '만족한 경헙에 대한 표현', '도전과 기술의 일치 및 환경에 대한 통제감' 등과 같은 공통적인 구성요소를 추출 해낼 수 있다(Csikszentmibalyi, 1977; Csikszentmihalyi and Csikszentmihalyi, 1988; Massimini and Carli, 1988; LeFerve, 1988; Csikszentmihalyi, 1990; Ghani. Supnick and Rooney, 1991; Eli is, Voelkl and Morris, 1994; Ghani, and Deshpande, 1994; Hoffman and Novak, 1996; Novak, Hoffman, and Yung; 1998). 즉, 플로우라는 것은 어떤 행위가 도 전으로 느껴지고 그 것을 할 수 있는 기술을 지녔을 때 도달되는 상태로 재미와 즐거움과 기뽐올 느끼는 최적의 경헙이라고 정의할 수 있다. 


\section{3. 연구설계}

\section{1 연구가설의 도출}

3.1 .1 인터넷 서비스 접점과 서비스품질간의 연구가설 도출

Bitner, Brown, and Meuter(2000)가 제시한 인터넷 서비스접점 요소인 고객화/유연성 (customization/flexibility), 효과적인 서비스 회복(effectiveness service recovery), 예 상치 못한 기쁨(flow)이 디지털 기술의 효과적인 이용에 있어서 의미 있는 역할을 제공할 수 있는지를 검중하기 위해서 전반적 인터넷 서비스접점 품질의 결정요인 추출하고, 이들의 영향 관계를 살펴보기 위해서 다음과 같은 가설을 세시하였다. 즉 디지털 기술이 기업과 고 객 모두에게 가치 있는 편익(benefit)을 제공하기 위해서 어떤 조건들이 선행되어야 하는지 를 확인하기 위해서 고객화, 서비스회복, 풀로우와 서비스접점 품질간의 관계를 검중하고자 하였다.

$\mathrm{H} 1$ : 개별화가 높을수록 인터넷서비스접점 품질은 높아질 것이다

$\mathrm{H} 2$ : 서비스회복노력이 높을수록 인터넷서비스접점 품질은 높아질 것이다

$\mathrm{H} 3$ : 풀로우 정도가 높을수록 인터넷서비스접점 품질은 높아질 것이다

3.1 .2 인터넷 서비스접점과 고객만족간의 연구가설 도출

고객화/유연성(customization/flexibility), 효과적인 서비스 회복(effectiveness service recovery), 예상치 못한 기쁨(flow)과 인터넷 서비스접점 품질, 인터넷 서비스접점 만족간의 관계에서 고객화, 서비스희복, 예상치 못한 기쁨이 직접적으로 인터넷 서비스접점 만족에 영향을 미치는지, 아니면 3 가지 결정요인이 인터넷 서비스접점 품질올 통해 인터넷 서비스접점 만족에 영향을 미치는지률 확인하기 위하여 다음과 같은 연구가설을 제시한다.

$\mathrm{H} 4$ : 개별화가 높을수록 인터넷서비스접점 만족이 높아질 것이다

H5 : 서비스회복노력이 높을수록 인터넷서비스접점 만족이 높아질 것이다

H6 : 플로우 정도가 높을수록 인터넷서비스접점 만족이 높아질 것이다

$\mathrm{H7}$ : 지각된 인터넷서비스품질이 높을수록 인터넷서비스접점 만족은 높아질 것이다

\section{1 .3 개별화 서비스희복 플로우간의 연구가설 도출}

기존 연구들의 고찰에서 살펴 본 바와 같이 개별화 서비스회복 플로우 개념은 이론적으로 독립적인 차원에서 연구되어져 왔지만, 3 가지 요인은 고객을 위한 서비스접점 경헙 (service encounter experience) 개선에 있어서 상호간에 영향을 미칠 수 있으므로 3 가지 개념간에 관계가 있는지를 검종하기 위하여 다음과 같은 연구가설을 제시한다

H8 : 개별화와 서비스 회복은 서로 유의한 영향을 미칠 것이다.

H9 : 서비스희복과 플로우는 서로 유의한 영향울 미칠 것이다.

$\mathrm{H} 10$ : 개별화와 플로우는 서로 유의한 영향을 미칠 것이다. 


\section{2 연구모형}

본 연구는 인터넷 서비스접점 품질의 영향요인을 분석하고, 이러한 인터넷 서비스접점 품 질과 고객만족간의 관계를 검중하기 위하여 기존 이론들을 기반으로 <그림 $2>$ 와 같은 통합 적인 연구모형을 제시한다.

\section{<그립 2> 연구모형}

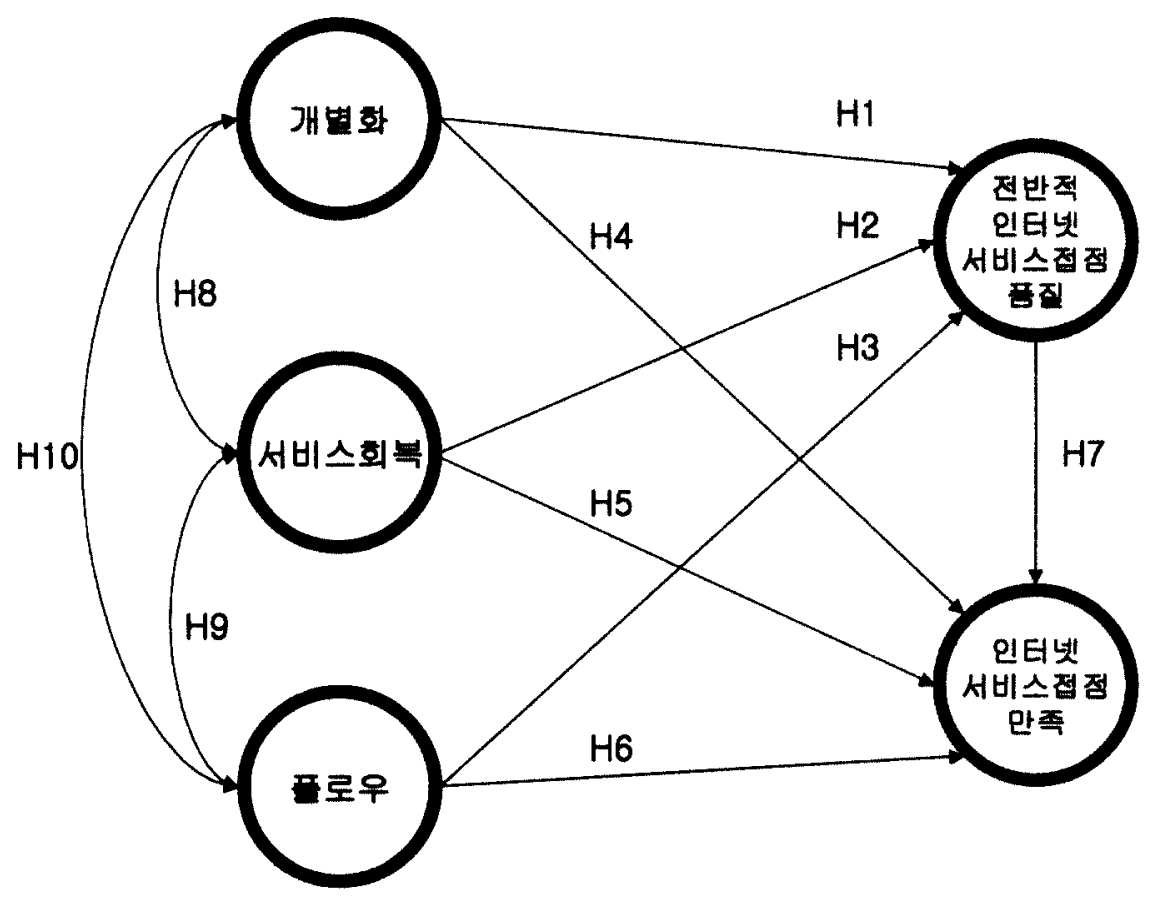

\section{3 표본설계}

본 연구를 위해 인터넷을 사용한 경헙이 있는 이용자룰 대상으로 총 300 부를 서울 60 부, 강원도 춘천 90 부, 속초 50 부, 원주 50 부, 강룽 50 부를 배포하여, 총 268 부가 회수되었 다(회수율 89\%). 지역별로 서울이 54 부, 춘천이 85 부, 속초 39 부, 원주 42 부, 강룽 48 부 가 회수되었다.

본 연구에 이용된 설문지는 작성자가 가장 최근 접속한 사이트를 대상으로 하였기 때문에, 가장 최근에 접속한 사이트의 특성이 연구에 중요한 요소로서 영향올 미칠 수 있다. 접속한 사이트의 특성을 보면, 다음(www.daum.net)이 136 명으로 전체에 $50.7 \%$ 를 차지하고 있으며 그 다음으로는 야후(24), 하늘사랑(13), 네이버(9), 라이코스(7), 엠파스 벅스뮤직 프리첼 (6), 웹진(5), 옥션 코리아닷컴 모교사랑(4), 기타가 44 개로 나타났다. 접속 유형별로 살 
펴보면, 메일이 $127(47.4 \%)$ 으로 가장 많았으며, 그 다음으로는 커뮤니티(16.8\%), 검색 (10.8\%)으로 나타났다.

<표 1> 표본의 접속 사이트 톡성

\begin{tabular}{|c|c|c||c|c|c|}
\hline \multicolumn{3}{|c|}{ 접속사이트 특성 } & \multicolumn{3}{c|}{ 접속 유형별 특성 } \\
\hline 구분 & 옹답자수 & \$ & 구분 & 웅답자수 & \% \\
\hline 다음 & 136 & 50.7 & 메일 & 127 & 47.4 \\
\hline 야후 & 24 & 9.0 & 커뮤니티 & 45 & 16.8 \\
\hline 스카이러브 & 13 & 4.9 & 검색 & 29 & 10.8 \\
\hline 네이버 & 9 & 3.4 & 뉴스정보 & 13 & 4.9 \\
\hline 라이코스 & 7 & 2.6 & 게임 & 12 & 4.5 \\
\hline 엠파스 & 6 & 2.2 & 전자상거래 & 10 & 3.7 \\
\hline 벅스뮤직 & 6 & 2.2 & 방송 & 4 & 1.5 \\
\hline 기타 & 67 & 25.0 & 기타 & 28 & 10.4 \\
\hline 계 & 268268 & $100 \%$ & & 268 & $100 \%$ \\
\hline
\end{tabular}

\section{4. 변수의 조작적 정의 및 척도}

\subsection{1. 인터넷 서비스접점 품질의 결정요인}

본 연구에서는 개별화를 Bettencourt and Gwinner(1996), Bitner et al,(1990), $\mathrm{Kelly}$ (1993)에서와 같이 "각 개인에게 적용되는 개별적인 서비스"로 정의하고 Winsted(1999)의 연구에서 사용된 측정항목을 이용하였으며, 3 가지 항목올 리커트 7 점(1 점: 매우 그렇다 7 점: 전혀 그렇지 않다)로 평가하였다. 측정 항목 내용은 '(1)내가 원할 때 언제든지 이용', '(2)나에게만 적용되는 개별적인 서비스 제공', '(3)나의 이름울 사용' 이었다.

서비스 회복은 세 가지 측면, 즉 분배 공정성(distributive justice), 절차정당성 (procedural justice), 상호작용정당성(interactional justice)에서 Smith et al(1999), Tax et al(1998), Oliver and Swan(1989), Clemmer and Schneider(1996)의 축정항목을 중심 으로 각각 2 가지 측정항목을 도출하였다. 또한 본 연구에서 정당성을 공정하고 정당하게 서비스가 제공되고 처리되는 것으로 정의한다. 각각의 항목은 리커트 7 점(1 점: 매우 그렇 다 7 점: 전혀 그렇지 않다)로 평가하였다. 6 가지 항목은 '(1)당연히 받아야 할 것을 제공 ', '(2)내가 제공받은 결과물은 공정', '(3)문제를 해결하는 방법을 준비', '(4)이용하기 위한 절차가 간편', '(5)이용방법이나 문제발생의 원인에 대해 충분히 설명', '(6)문제해결 이나 서비스 개선을 위해 충분한 노력'이었다.

기존 off-line 비즈니스에서는 예상치 못한 기뽐의 제공을 놀라움을 동반한 즐거운 감정 으로 정의하고 있다. 그러나 on-line 에서는 이러한 기뽐울 플로우라는 개념으로 정의하고 설명하고 있다. 본 연구에서는 이러한 기뽐의 제공울 플로우개념에서 정의한 Novak, Hoffman and Yung(1999)의 개념와 Oliver et al(1997)의 개념을 결합하여 3 가지 항목, 즉 놀라움(surprised), 기쁨(delighted), 매우 즐거운 경헙(flow)을 개발하였다. 각각의 항목 
은 리커트 7 점 (1 점: 매우 많이 느꼈다, 7 점: 전혀 느끼지 못했다)로 평가하였다

\section{4 .2 전반적 인터넷 접점 서비스 품질}

전반적인 서비스품질은 많은 연구에서 단일항목이나 복수항목으로 측정되어지만, 전반적 인 서비스품질을 단일항목으로 측정하는 것은 고객만족이나 구매의도와 같은 연구단위들간 의 구조적 관계를 설명하기에는 부족한 점이 있다(Parasuraman, Zeithaml and Berry, 1994). 본 연구에서는 서비스품질을 웹사이트의 전반적 품질 지각정도로 정의하고, 이학식 - 유동근 이용기(1997)가 사용한 세 가지 측정항목을 적용하였다. 전반적인 품질을 어떻게 생각하고 있는지를 리커트 7 점 척도로 평가하였다. 3 개 항목은 '(1)매우 높게 생각한다-매우 낮게 생각한다, (2)매우 훌륭하게 생각한다-매우 형편없이 생각한다, (3)매우 마음에 든다-전혀 마음에 들지 않는다'이다.

3.4 .3 전반적인 인터넷 서비스 접점 만족

본 연구에서는 인터넷 서비스 접점 만족올 특정 웹사이트를 접속해 있는 동안의 만족이라 고 정의하고, Simth et al(1999)의 연구에서 사용한 측정항목과 기대 대비 성과의 만족도를 함께 측정하였다. 3 가지 항목은 '(1)매우 만족했다-전혀 만족하지 못했다, (2)매우 그렇 다-전혀 그렇지 않다. (3)생각했던 것보다 훨씬 좋았다-생각했던 것보다 휠씬 못 미쳤다'이 다.

\section{4. 실증분석}

\section{1 척도의 정제}

본 연구에서는 각 차원들의 타당성과 신뢰성을 측정하기 위하여 Sigh 과 Rhoads(1991)가 제시한 척도정제(scale refinement) 절차를 적용하였다. 척도의 정제는 SPSS 10.0 프로그램 과 AMOS 4.0 프로그램을 이용하였다.

\subsection{1 탐색적 요인분석과 신뢰성분석}

먼저 각 연구단위별로 SPSS 10.0 을 이용하여 사각회전(oblique ratation)방식에 의한 최 우도추정법(maximum likelihood : ML)에 의거하여 탐색적 요인분석(exploratory factor analysis : $\mathrm{EFA}$ )을 실시하였다. 평가기준으로서 요인적재값 0.3 이상, 요인의 설명력(the variance extracted)은 0.5 이상을 설정하였다(Bagozzi and Yi, 1988; Challaglla and Shervani, 1996; Hair, Anderson, Tatham, and Black, 1998; Singh and Rhoads, 1991; 이 학식 등, 1998). 탐색적 요인분석의 결과, 평가기준을 충족시키지 못한 서비스회복의 측정 항목 중 2 개의 항목이 제외되었다. 나머지 연구단위들의 측정항목들을 평가기준에 위배되 지 않았다. 탐색적 요인분석 결과 남은 항목들에 대하여 신뢰성을 조사하기 위하여 SPSS 10.0 을 이용하여 Cronbach's a 를 계산하였다. 신뢰성분석 결과 <표 2>에 나타난 것처럽 신뢰성올 저하시키는 항목온 없었으며, 최종 항목 수률 기초로 한 신뢰성 값은 0.7593 0.8505 사이에 있어 신뢰성이 높은 것으로 나타났다. 
<표 2> 탐색적 요인분석과 신뢰성분석 결과

\begin{tabular}{|c|c|c|c|c|c|}
\hline 연구단위 & $\begin{array}{c}\text { 쳐초 } \\
\text { 항록수 }\end{array}$ & $\begin{array}{c}\text { 사갛희전 } \\
\text { 제거 }\end{array}$ & $\begin{array}{c}\text { 사각혀전 } \\
\text { 결과 }\end{array}$ & $\begin{array}{c}\text { 신쾨성 } \\
\text { 분석결과 }\end{array}$ & a 계수 \\
\hline 개별화 & 3 & - & 3 & 3 & 0.7593 \\
\hline 서비스회복 & 6 & $\begin{array}{c}\text { factor loading 값 } \\
(3 \text { 항목:0.171) } \\
(5 \text { 항목:0.262) } \\
2 \text { 개 항목 제거 }\end{array}$ & 4 & 4 & 0.7696 \\
\hline 플로우 & 3 & - & 3 & 3 & 0.7965 \\
\hline 서비스품질 & 3 & - & 3 & 3 & 0.8164 \\
\hline 만족 & 3 & - & 3 & 3 & 0.8505 \\
\hline
\end{tabular}

\section{1 .2 확중적 요인분석}

앞의 1 차분석을 거친 항목에 대하여 각 구성개념별로 확인요인분석(CFA; Confirmatory Factor Analysis)을 실시하였다. 확인요인분석은 각 차원에 대하여 미리 규정된 관계를 검 정하는 다변량분석기법을 의미한다(Hair et al., 1998). 확중적 요인분석은 신뢰성검증이 내적일관성올 가정하지만 검중하지 못하기 때문에 널리 이용되고 있다. 이들 구성개념의 적 합도를 평가하기 위한 지표로 GFI(Goodnes-of-Fit Index: 0.90 이상이 바람직함), AGFI(Adjusted Goodness-of-Fit Index: 0.9 이상이 바랍직합), RMSR(Root Mean Square Residual:0.05 이하이면 바람직함), 카이자숭(적을수록 바람직함), 카이자숭에 대한 $\mathrm{p}(0.05$ 이상 이면 바람직합)을 적용하였다. 또한 중분적합지수인 NFI(Normed Fit Index:0.9 이상이 면 바람직함)을 이용하였다. <표 3>는 확인요인분석을 나타내고 있다. 여기서 이론적 변수 를 구성하는 항목에서 개별화, 플로우, 품질, 만족 측정 항목은 변수의 개수가 3 개 이하로 기준치(indicators 3 개 = perfect)를 충족시키고 있으므로 확중적 요인분석에서 제외되었 다.

<표 3> 확중적 요인분석 결과

\begin{tabular}{|c|c|c|c|c|c|c|c|c|c|}
\hline 요인 & $\begin{array}{c}\text { 초기 } \\
\text { 항목 }\end{array}$ & $\begin{array}{c}\text { 최중 } \\
\text { 항목 }\end{array}$ & GFI & AGFI & RMSR & NFI & $\begin{array}{c}\text { Chi- } \\
\text { square }\end{array}$ & d.f & p \\
\hline 서비스회복 & 4 & 4 & 0.994 & 0.971 & 0.042 & 0.985 & 3.180 & 2 & 0.204 \\
\hline $\begin{array}{c}\text { 개별화/플로우/품질/만 } \\
\text { 족 }\end{array}$ & \multicolumn{8}{|c|}{ indicators 3 개 = perfect } \\
\hline
\end{tabular}

서비스희복을 구성하는 하위차원돌에 대하여 확중적 요인분석올 실시한 결과, 구성개념의 모든 적합도 평가기준보다 높온 것으로 나타나 현재의 수준을 그대로 분석에 이용하였다. 하나의 요인올 구성하는 변수들의 적재치가 높은 경우, 변수들의 합 또는 변수들의 합에 대 한 평균을 통해서 새로운 변수를 생성할 수 있는데 이것을 총합척도(summated scale)라고 
한다(Hair et al., 1998). 총합척도의 이용은 측정오차 정도를 줄여 주고 단일변수로 많은 측면올 대변할 수 있는 능력을 제공한다(김계수, 2001). 본 연구에서 사용된 설문항목들은 앞의 분석결과에서도 나타난 것처럼 각 이론적 개념을 구성하는 변수들 간의 요인 적재치가 매우 높은 것으로 나타나고 있다. 따라서 최종모형에 대한 검중과 가설 검중에 충합척도를 이용하였다.

\section{2 측정모형분석}

모형의 적합성 평가와 가설검중을 하기 위해서 AMOS 4.0 통계 프로그램을 이용하여 모형 적합지수 분석, 경로계수분석을 실시하였다

\subsection{1 모형의 적합성 평가}

본 연구의 전체적 구조모델(overall model)을 검중한 결과, $\chi 2=96.136, \mathrm{df}=84$ (자유도), $\mathrm{p}$ 값 $=0.172, \mathrm{GFI}=0.957, \mathrm{AGFI}=0.931, \mathrm{RMR}=0.07, \mathrm{NFI}=0.952$ 의 결과가 도출되었다. <표 $4>$ 의 평가기준의 지표와 비교할 때 RMR 이 기준치를 충족시키지 않으나, 나머지 지수들이 모두 평가기준을 충족시키기 때문에 전체적 구조모델의 적합도 기준에 일치하는 것을 알 수 있다.

<표 4> 구조모델 적합성 평가 결과

\begin{tabular}{|c|c|c|c|c|}
\hline 구분 & 부합지수 & 적합도 기준 & 적합성지수 & 수용수준 \\
\hline \multirow{4}{*}{ 절 대부합지수 } & $\begin{array}{c}x^{2} \\
\text { (카이자숭 뿡계량) }\end{array}$ & 0.05 이상 & $\begin{array}{c}x 2=96.136 \\
d f=84 \\
p=0.172\end{array}$ & $\begin{array}{c}\text { 한계지지 } \\
\text { (marginal) }\end{array}$ \\
\hline & $\begin{array}{c}\text { GFI } \\
\text { (기초부합지수) }\end{array}$ & 1 & 0.957 & 한계지지 \\
\hline & $\begin{array}{c}\text { AGFI } \\
\text { (조정부합치) }\end{array}$ & 1 & 0.931 & 한계지지 \\
\hline & $\begin{array}{c}\text { RMR } \\
\text { (원소간 평균차이) }\end{array}$ & 0.05 이하 & 0.07 & $\begin{array}{c}\text { 부적절 } \\
\text { (not appliable) }\end{array}$ \\
\hline 증분부합지수 & $\begin{array}{c}\text { NFI } \\
\text { (표준부합지수) }\end{array}$ & 1 & 0.952 & 한계지지 \\
\hline
\end{tabular}

\subsection{2 인과분석 (가설검중)}

각 요인별 구조방정식모형 분석결과는 <그림 3 과 같이 나타낼 수 있다. 이것을 표로 간단 히 나타내면 <표 $5>$ 과 같다. 
<그림 3> 모형분석 결과

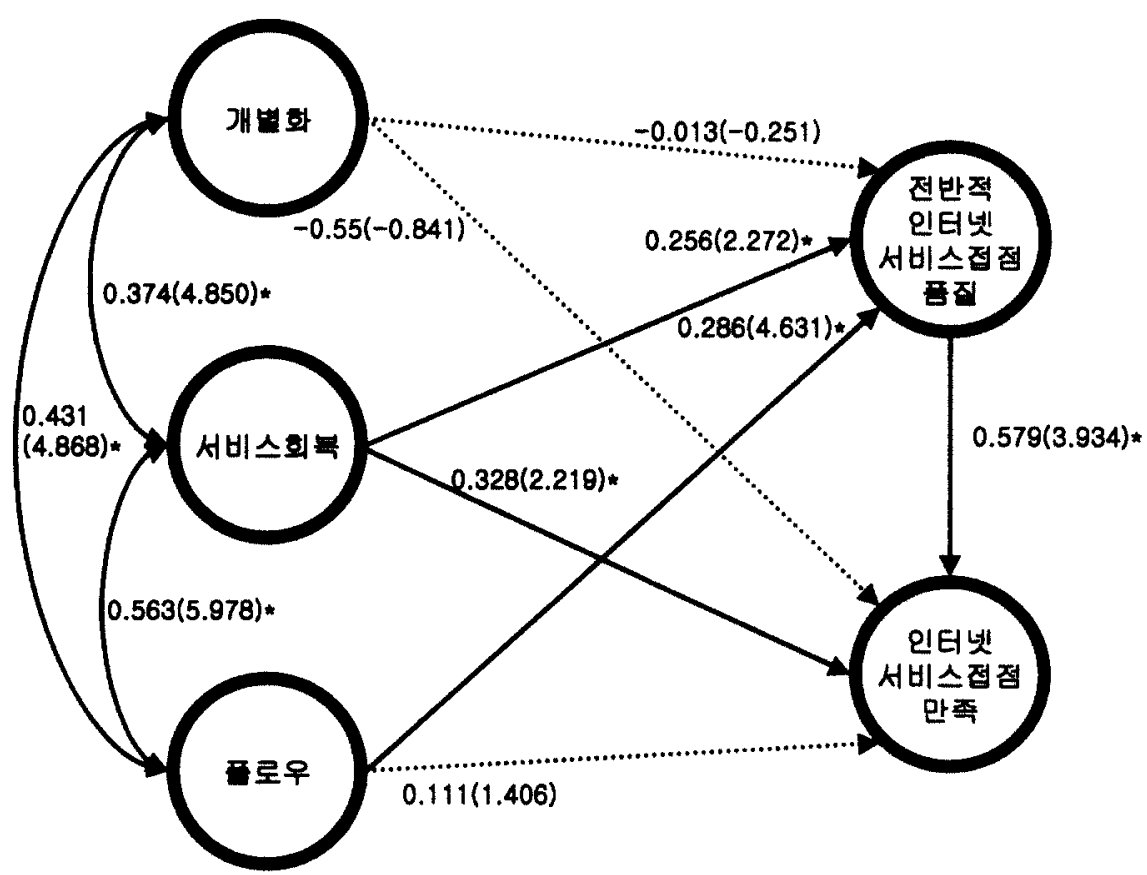

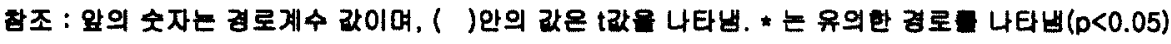

<표 5> 경로계수와 공분산

\begin{tabular}{|c|c|c|c|c|c|}
\hline \multicolumn{6}{|c|}{ 경로계수분석 결과 } \\
\hline 가설 & 경로 & 경로계수 & t 값 & sig. & 가설검중 \\
\hline H1 & 개별화 $\rightarrow$ 품질 & -0.013 & -0.251 & 0.802 & 기각 \\
\hline H2 & 서비스희복 $\rightarrow$ 품질 & 0.256 & 2.272 & 0.023 & 지지 \\
\hline $\mathrm{H} 3$ & 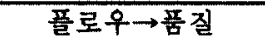 & 0.286 & 4.631 & 0.000 & 지지 \\
\hline H4 & 개별화 $\rightarrow$ 만족 & -0.055 & -0.841 & 0.400 & 기각 \\
\hline H5 & 서비스희복 $\rightarrow$ 만족 & 0.328 & 2.219 & 0.026 & 지지 \\
\hline H6 & 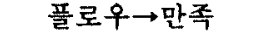 & 0.111 & 1.406 & 0.160 & 기각 \\
\hline H7 & 품질 $\rightarrow$ 만족 & 0.579 & 3.934 & 0.000 & 지지 \\
\hline \multicolumn{6}{|c|}{ 공분산분석 결과 } \\
\hline H8 & 개별화 $\leftrightarrow$ 서비스회복 & 0.374 & 4.850 & 0.000 & 지지 \\
\hline H9 & 서비스회복 $\leftrightarrow$ 풀로우 & 0.563 & 5.978 & 0.000 & 지지 \\
\hline $\mathrm{H} 10$ & 개별화 $\leftrightarrow$ 풀로우 & 0.431 & 4.868 & 0.000 & 지지 \\
\hline
\end{tabular}

첫 번째로 경로계수와 $\mathrm{t}$ 값, 유의수준을 분석하여 3.3 .1 의 가설욜 검중한 결과를 살펴보 
면, 첫째, 개별화가 늪을수록 인터넷서비스접점 품질이 높아질 것이라는 연구가설 1 을 검 증한 결과, 유의수준을 충족하지 못하는 것으로 나타넜다. 또한 정 $(+)$ 의 효과률 미치지 못 하는 것으로 나타나 연구가설 1 은 지지되지 않았다. 둘째, 인터넷서비스 회복 노력(정당성) 이 높을수록 인터넷서비스접점 품질이 높아질 것이라는 연구가설 2 를 검증한 결과, 서비스 회복은 인터넷서비스접점 품질에 유의적인 정 $(+)$ 의 영향올 미치는 것으로 나타나 연구가설 2 는 지지되었다. 쎗째, 폴로우가 높을수록 인터넷서비스접점 품질이 높아질 것이라는 연구 가설 3 을 검증한 결과, 플로우가 인터넷서비스접점 품질에 유의적인 정 $(+)$ 의 효과를 미치 는 것으로 나타나. 연구가설 3 은 지지되었다.

두 번째로 경로계수와 $\mathrm{t}$ 값, 유의수준올 분석하여 3.3 .2 의 가설을 검중한 결과를 살펴보 면, 첫째, 개별화가 높을수록 고객만족이 높올 것이라는 연구가설 4 를 검중한 결과, 유의 적인 정 $(+)$ 의 영향을 주지 못하는 것으로 나타나 연구가설 4 는 지지되지 않았다. 둘째, 인 터넷서비스회복 노력이 높을수록 고객만족이 높을 것이라는 연구가설 5 를 검중한 결과, 유 의적인 정 $(+)$ 의 효과를 미치는 것으로 나타나 연구가설 5 는 지지되었다. 셋째, 풀로우가 높을수록 고객만족이 높아질 것이라는 연구가설 6 을 검중한 졀과, 정 $(+)$ 의 관계는 있으나 유의적인 수준올 넘지 못하는 것으로 나타나 연구가설 6 은 지지되지 못하였다. 넷째, 인터 넷서비스접점 품질이 높을수록 고객만족이 높아질 것이라는 연구가설 7 을 검중한 결과, 유 의적인 정(t)의 효과에 영향을 주는 것으로 나타나 연구가설 7 은 지지되었다.

세 번째로 공분산 분석결과를 토대로 개별화 서비스희복 플로우 개넘간의 관계를 검증한 결과를 살펴보면, 첫째, 개별화와 서비스회복 개넘간에 유의한 정(t)의 관계가 있을 것이라 는 연구가설 8 을 검중한 결과, 두 개념간에는 유의적인 정 $(+)$ 의 관계가 있을 것으로 나타 나 연구가설 8 은 지지되었다. 둘째, 서비스회복과 플로우간에 유의한 정 $(+)$ 의 관계가 있을 것이라는 연구가설 9 를 검중한 결과, 두 개념간에는 유의적인 정 $(t)$ 의 관계가 있을 것으로 나타나 연구가설 9 는 지지되었다. 셋째, 개별화와 플로우간에 유의한 정 $(+)$ 의 관계가 있을 것이라는 연구가설 10 을 검증한 결과, 두 개념간에는 유의적인 정 $(+)$ 의 관계가 있올 것으 로 나타나 연구가설 10 은 지지되었다.

\section{2 .3 인과효과분석}

본 연구모형의 요인간에 전체적인 영향력을 분석하였다. 여기서 전체적인 영향력은 인과 효과(causal effect)로, 인과효과는 직접효과(direct effect)와 간접효과(indirect effect) 로 나누어 분석할 수 있다. 직접효과란 두 요인사이의 직접적인 경로계수를 의미하고, 간접 효과란 매개적인 요인이 영향을 주는 것을 의미한다. 본 연구의 직접효과와 간접효과를 분 석한 결과는 <표 6>과 같다.

<표 6> 인과효과의 분해

\begin{tabular}{|c|c|c|c|}
\hline 가설경로 & 직접효과 & 간접효과 & Causal Effect \\
\hline 풀로우 $\rightarrow$ 품질 & 0.286 & - & 0.286 \\
\hline 플로우 $\rightarrow$ 만족 & 0.111 & 0.166 & 0.276 \\
\hline 서비스희복 $\rightarrow$ 품질 & 0.256 & - & 0.256 \\
\hline 서비스희복 $\rightarrow$ 만족 & 0.328 & 0.148 & 0.476 \\
\hline 품질 $\rightarrow$ 만족 & 0.579 & - & - \\
\hline
\end{tabular}


인과효과분석 결과률 살펴보면, 인터넷 서비스접점 만족에 가장 큰 영향을 미치는 것이 지각된 인터넷 서비스접점 품질(직접효과 $=0.579$ )인 것으로 나타넛다. 풀로우와 만족, 서비 스회복과 만족에 간접효과가 존재하는 것으로 나타넜다. 이러한 결과는 플로우와 서비스화 복이 직접적으로 인터넷 서비스접점만족에 영향을 미치는 것이 아니라, 선행변수로 지각된 인터넷 서비스접점 품질이 존재한다는 것을 의미한다.

\section{5. 결 론}

\section{1. 연구의 요약 및 시사점}

본 연구는 Bitner, Brown and Meuter(2000)의 인터넷 서비스접점 증대방법의 문헌적 전개 를 기초로 해서 실제적으로 개별화, 서비스회복노력, 풀로우 개념이 인터넷 서비스접점에서 품질과 만족에 영향을 미치는 요인인지에 대하여 살펴보고자 하였다.

본 연구에서 제시하고 있는 연구모형과 연구가설에 대한 실중분석 결과와 그에 따른 시사 점들을 살펴보면 다음과 같다.

첫째, 개별화(flexibility), 지각된 인터넷 서비스접점 품질과 고객만족과의 관계를 실중 적으로 분석한 결과, 개별화가 인터넷 서비스접점 품질(internet service encounter quality)에 영향을 미치는 못하는 것으로 나타났으며 또한 고객만족에도 영향올 미치는 못 하는 것으로 나타났다. 개별화에 관한 3 가지 질문은 척도정제과정에서 비록 모두 유의한 것으로 나타넜지만, 3 가지 질문을 구체적으로 살펴보면, "나에게만 적용되는 개별적인 서 비스 제공(평균 $=3.1082$ )"에 대한 웅답이 다른 2 가지 웅답(평균 $=2.1530$-내가 원할 때 언제 든지 이용, 2.5373-나의 이름을 사용) 보다 부정적인 것으로 나타나 전반적인 인터넷서비스 접점 품질과 고객만족에 영향을 주지 못하는 것으로 나타나고 있는 것으로 판단된다. 즉, 개별화 이전에 접근 용이성과 같은 인터넷 서비스 시스템의 구축이 선행되어야 한다는 것을 의미하고 있는 것으로 보여진다. 하지만, Quinn(1996)이 서비스 제공에 있어서 유연성(개별 화)이 인터넷으로 인해 가능해진 가장 중요한 품질 개선의 하나라고 주장하는 것을 국내 인 터넷서비스기업이 간과해서는 안될 것이다.

둘째, 서비스회복(justice), 지각된 인터넷 서비스접점 품질과 고객만족과의 관계를 실증 적으로 분석한 결과, 인터넷 서비스 회복노력이 인터넷 서비스접점 품질과 고객만족에 모두 유의한 정 $(t)$ 의 영향올 미치는 것으로 나타나 Bitner, Booms, and Tetreult(1990)의 주장과 일치하였다. 즉 인터넷 서비스 실패가 일어난 경우에 인터넷 서비스 기업이 문제해결을 위 한 적극적인 노력을 기울인 경우에는 오히려 고객들은 긍정적인 태도를 보인다는 것이다.

셋째, 플로우, 지각된 인터넷 서비스접점 품질과 고객만족과의 관계를 실증적으로 분석한 결과, 플로우가 지각된 인터넷 서비스접점 품질에 영향올 주는 것으로 나타났다. 이는 Hoffman 과 Novak(1996)의 주장과 일치하는 것으로 인터넷마케팅전략에 플로우가 유용한 개 념이라는 것을 보여주고 있다. 반면 플로우가 고객만족에는 영향을 주는 못하는 것으로 나 타났다. 그러나 인과효과분석(causal effects analysis) 결과 인터넷 서비스접점품질이 고 객만족에 선행하는 것으로 나타나, 중요한 매개적 요인임올 중명해 주고 있다. 
넷째, 지각된 전반적 인터넷 서비스접점 품질과 고객만족과의 관계를 실중적으로 분석한 결과, 지각된 인터넷서비스접점 품질이 고객만족에게 영향을 주는 것으로 나타넜다. 이는 서비스품질과 만족간의 최근 연구들(Cronin and Taylor 1992; Lee, Lee, and Yoo, 1999; Reidenbach and Sandifer-Smallwood, 1990)에서 중명된 서비스품질이 만족에 선행한다고 주 장과 일치하고 있다.

다섯째, 개별화 서비스희복 플로우 간의 상호관련성올 실중분석 한 결과, 3 가지 개념은 서로 독립적인 단일차원이 아니라 상호간에 영향을 주는 것으로 나타났다. Bitner, Brown and Meuter (2000)은 인터넷서비스접점의 중대방법요소로 3 가지률 중요한 요소로 언급하고 있는데, 본 연구의 실중적 분석 결과를 살펴보면 개별화 서비스회복 풀로우가 인터넷서비스 접점에서 서로 연관성이 있으며 이러한 요소들이 모두 중요하다는 결론을 도출할 수 있다.

\section{2. 연구의 공헌 · 한계점 · 앞으로의 연구방향}

본 연구는 급변하고 있는 디지털환경에서 우수한 인터넷서비스제공을 위해 마케터들이 무 엇을 중요한 개념으로 삼아야 할 것인지에 대한 이론적 근거를 제공하고 있다. 단일차원에 서 언급되어지고 있는 인터넷서비스의 개별화, 서비스회복, 풀로우의 개념의 상호관련성과 이러한 개념들이 인터넷서비스접점 품질과 고객만족에 영향을 미치는지를 실중분석 합으로 써 기존의 문헌적 연구와 실중적 연구성과를 종합적으로 고찰하였다는데 그 이론적 의의가 있다.

그러나 본 연구는 다음과 같은 한계점을 가지고 있다. 첫째, 인터넷기업들의 접점 서비스 는 지속적인 노력에 의해서 그 성과가 나타나는데 비하여 본 연구는 횡단적인 연구를 하였 다. 따라서 향후에는 중단적인 연구시도가 이루어져야 할 것이다. 둘째, 개별화, 서비스회 복, 플로우의 개념은 각각 하위차원의 구성요소를 가지고 있지만, 본 연구에서는 하위차원 보다는 전체적인 개념에 초점을 두어 연구단위의 척도가 충분하지 못했다. 향후에는 이러한 연구단위의 세부적인 하위차원들도 척도로 개발할 수 있을 것이다. 셋째, 본 연구의 표본추 출이 일부지역(서울, 춘천, 속초, 원주, 강룽)에 국한되어 표본의 대표성에 관한 한계점을 가지고 있다. 넷째, 본 연구는 웅답자가 가장 최근 접속한 사이트를 대상으로 실중분석을 했기 때문에, 접속사이트 특성과 유형에서 한계를 들어내고 있다. 분석대상 사이트를 살펴 보면, 다음(nww.daum.net)이 전체에 50.7\%를 차지하고 있다. 또한 접속종류와 유형을 살펴 보면 메일유형이 전체에 $47.4 \%$ 를 차지하고 있다. 즉 daum 과 메일유형이 분석대상사이트에 절반을 차지하고 있어 인터넷서비스의 대표성을 가지고 있지 못한 것으로 판단된다. 향후 접속유형과 특성별로 카테고리를 나누어 실중적 분석결과를 비교해 볼 수 있올 것이다. 


\section{<참고문헌>}

김계수(2001), AMOS 구조방정식 모형분석, SPSS 아카데미.

이학식, 유동근, 이용기(1997), "서비스품질지각, 고객만족, 재구매의도의 관계," Working Paper.

이학식, 김영(1997), "연구디자인이 Cronbach's a 계수에 미치는 영향에 관한 연구," 한국 마케팅학회, 마케팅연구, 12(1), 209-221.

이학식, 김영(1999), "서비스품질과 서비스가치," 한국마케팅학희, 한국마케팅저널, 1(2), 77-99,

한상린, 박천교(2000), "FLOW 개념을 이용한 인터넷 환경에서의 소비자 구매의도 결정요인

분석," 한국마케팅학희, 마케팅연구, 15(1), 187-204.

허준 최인규(2000), ANOS 를 이용한 구조방정식 모형과 경로분석, SPSS 아카테미

Bagozzi, R. and Y. Yi(1998), "On the Evaluation of Structural Equation Models," Journal of Academy of Marketing Science, Vol. 16(4), 257-269.

Bettencourt, Lance A. and Kevin Gwinner(1996), "Customer of the Service Experience: The Role of the Frontline Employee," International Journal of Service Industry Management, 7(2), 3-20.

Bitner, Mary Jo.(1990), "Evaluating Service Encounter: The Effects of Physical Surrounding and Employee Responses," Journal of Marketing, Vol. 54(April), 69-82.

Bernard H. Booms and Mary Stanfield Tetreault(1990), "The Service Encounter: Diagnosing

Favorable and Unfavorable Incidents," Journal of Marketing, Vol. 54(Jan), 71-84.

(1992), "Servicescapes: The Impact of Physical Surroundings on Customers and Employees," Journal of Marketing, Vol. 56(April), pp.57-71.

and Lois A. Mohr(1994), "Critical Service Encounters: The Employee's Viewpoint," Journal of

Marketing, Vol. 58(Oct), 95-106.

(1995), "Building Service Relationship: It's All About Promises," Journal of Academy of Marketing Science, Vol. 23(4), 246-251.

Stephen W. Brown and Matthew L. Meuter(2000), "Technology Infusion in Service Encounters," Journal of Academy of Marketing Science, Vol. 28(1), 138-149.

Blodgett, Jeffrey G, Donna J. Hill, and Stephen S. Tax(1997), "The Effects of Distributive, Procedural and Interactional Justice on Postcomplaint Behavior," Journal of Retailing, Vol. 73(2), 185-210.

Challaglla, Goutam N. and Tasaddug A. Shervani(1996), "Dimensions and Types of Supervisory Control: Effects on Salesperson Performance and Satisfaction," Journal of Marketing, Vol. 60(Jan), 89-105.

Clemmer, E. C. and B. Schneider(1996), "Fair Service" In S. W. Brown et. al. eds, Advances in Service Marketing and Management, Vol. 5, Greenwich, CT:JAI Press.

Cornin, J. Joseph and Steven A. Taylor(1992), "Measuring Service Quality: A Reexamination and Extension," Journal of Marketing, July, 55-68. , Michael K. Brady, Richard R. Brand, Roscoe Hightower Jr., and Dnonal J. Shemwell(1997), "A

Cross-Sectional Test of the effect and Conceptualization of Service Value," The Journal of Services Marketing, Vol. 16(6), 375-391.

Csikszentmihalyi, Mihaly(1977), Beyond Boredom and Anxiety, 2nd Printing, San Francisco, Jossey-Bass. and Isabella Csikszentmihalyi(1988), "Introduction to Part IV" in Optimal Experience:

Psycological Studies of Flow in Conciousness, M. Csikszentmihalyi and I. Csikszentmihalyi(eds), New York: Cambridge Unversity Press.

(1990), Flow: The Psychology of Optimal Experience, New York, Harper \& Row Publisher. 
Dabholkar, Pratibha A.(1996), "Consumer Evaluations of New Technology-Based Self-Service Options: An Investigation of Alternative Models of Service Quality," International Journal of Research in Marketing, Vol. 13(1), 29-51.

Ellis, Gray D., Judith E. Voelkl, and Catherine Morris(1994), "Measurement and Analysis Issues with Explanation of Variance in Daily Experience Using the Flow Model," Journal of Leisure Research, Vol. 26(4), 337-356.

Fornell, Claes, Michael D. Johnson, Eugene W. Anderson, Jaesung Cha, and Barbara Everitt Bryant(1996), "The American Customer Satisfaction Index: Nature, Purpos and Findings," Journal of Marketing, Vol. 60(Oct), 7-18.

Ghani, Jawaid A., Robetra Supnick and Pamela Rooney(1991), "The Experience of Flow in Computer Mediated and In Face-to-Face Groups," Proceedings of the Twelfth International Conference on Information System, Degrees, J. I., I. Benbasat, G DeSanctis, and C. M. Beath, Eds., New York, December, pp.16-18.

and Satish P. Desphande(1994), "Task Characteristics and the Experience of Optimal Flow in Human-Computer Interaction," The Journal of Psychology, Vol. 128(4).

Hair, Joseph F., Jr., Rolph E. Anderson, Ronald L. Tatham, and William C. Black(1995), Multivariate Data Analysis with Readings, Macmillan Publishing Company.

Hart, Christopher W. L., James L. Heskett, and W. Earl Sasser, Jr.(1990), "The Profitable Art of Service Recovery," Harvard Business Review, July-August, 148-156.

(1996), "Made to Order," Marketing Management, Vol. 5(2), 11-23.

Hoffman, Donna L. and Thomas P. Novak(1996), "Marketing in Hypermedia Computer-Mediated Environment: Conceptual Foundations," Journal of Marketing, Vol. 60(July), 50-68. Thomas P. Novak, and Ann Schlosser(2000), "Consumer Control in Online Environments," Working Paper, Vanderbilt University, February.

Keaveney, Susan M.(1995), "Customer Switching Behavior in Service Industries: An Exploratory Study," Journal of Marketing, Vol. 59(April), 71-82.

Kelly, Scott W.(1993), "Discretion and the Service Employee," Journal of Retailing, Vol. 69(Spring), 104 126.

Leaf, Clifton(1998), "The Death of Customer Service," Smart Money, October, 131-137.

Lee, Haksik, Yongki Lee, and Dongkeun Yoo(1999), "The Determinants of Perceived Quality and Its Relationship with Satisfaction," The Journal of Services of Marketing, forthcoming.

Manning H., John C. McCarthy, and Randy K. Souza(1998), Why Most Web Sites Fail, Interactive Technology Series, Vol. 3, No. 7, Forrester Research: September.

Massimini, Faustio and Massimo Carli(1988), "The Systematic Assessment of Flow in Daily Experience," In M. Csikszentmihalyi and I. Csikszentmihalyi(eds), Optimal Experience: Psychological Studies of Flow in Conciousness, New York: Cambridge University Press.

Novak, Thomas P. and Donna L. Hoffman(1997), "Measuring the Flow Experience among Web Users," Unpublished Working Paper, <http://www2000.ogsm. vanderbilt.edu/tnvita.html >

, Donna L. Hoffman, and Yiu-Fai Yang(1998), "Measuring the Flow Construct in Online Environments: A Structure Modeling Approach," Unpublished Working Paper<http://www2000.ogsm.vanderbilt.edu/tnvita.html >

Donna L. Hoffman, and Yiu-Fai Yang(1998), "Modeling the Structure of the Flow Experience Among Web Users," Paper presented for Marketing Science and Internet Conference, MIT, March. Donna L. Hoffman, and Yiu-Fai Yang(1999), "Measuring the Flow Construct in Online Environments: A Structure Modeling Approach," Unpublished Working Paper. <http://www2000.ogsm.vanderbilt.edu/tnvita.html > 
Donna L. Hoffman, and Yiu-Fai Yang(2000), "Measuring the Customer Experience in Online Environments: A Structural Modeling Approach," Marketing Science, Vol. 19(1), 2000. <http://www2000. ogsm.vanderbilt.edu/papers/flow.construct/measuring_flow_construct.html>

Oliver, Richard L.(1997), Satisfaction: A Behavioral Perspective on the Consumer, New York: McGrawHill.

Roland T. Rust, and Sajeev Varki(1997), "Customer Delight: Foundations, Findings, and Managerial Insight," Journal of Retailing, Vol. 73(3). 311-336. and John E. Swan(1989a), "Consumer Perceptions of Interpersonal Equity and Satisfaction in Transaction: A Field Survey Approach," Journal of Marketing, Vol. 53(April), 21-35. and John E. Swan(1989b), "Equity and Disconfirmation Perceptions as Influence on Merchant and Product Satisfaction," Journal of Consumer Research, Vol. 16(Dec), 372-383. and Wayne S. DeSarbo(1988), "Response Determinants in Satisfaction Judgment," Journal of Consumer Research, Vol. 14(March), 495-507.

Parasuraman A., Valarie Zeithaml, and Leonard Berry(1985), "A Conceptual Model of Service Quality and Its Implications for Future Research," Journal of Marketing, Vol. 49(Fall), 41-50. , Valarie Zeithaml, and Leonard Berry(1994), "Reassessment of Expectations as a Comparison Standard in Measuring Service Quality: Implications for Ruther Research," Journal of Marketing, Vol. 58(Jan), 111-124.

Quinn, James Brian(1996), "The Productivity Paradox Is False: Information Technology Improves Service Performance," In Advances in Service Marketing and Management, Vol. 5. Eds. Teresa A. Swartz, David E. Bowen and Stephen W. Brown, Greenwich, CT: JAI.

Rayport, Jeffery F. and John J. Sviokla(1994), "Managing in the Marketspace," Harvard Business Review, Vol. 72(Nov-Dec), 2-11.

and John J. Sviokla(1995), "Exploiting the Virtual Value Chain," Harvard Business Review, Vol. 73(Nov-Dec), 14-24.

Reidenbach, R. Eric and Beverly Sandifer-Smallwood(1990), "Exploring Perceptions of Hospital Operations by a Modified SERVQUAL Approach," Journal of Health Care Marketing, Vol. 10(Dec), 47-55.

Shostack, G Lynn(1985), "Planning the Service Encounter," The Service Encounter, John A. Czepiel, Michael R. Solomon, and Carol F. Suprenant, eds. New York: Lexington Books, 243-254.

Singh, Jagdip and Gary K. Rhoads(1991), "Boundary Role Ambiguity in Marketing-Oriented Positions: A Multidimensional, Multifaceted Operationalization," Journal of Marketing Research, Vol. 28(Aug), 328-338.

Smith, Amy K., Ruth N. Bolton and Janet Wagner(1999), "A Model of Customer Satisfaction with Service Encounters Involving Failure and Recovery," Journal of Marketing Research, Vol. 36(Aug), 356-372.

Surprenant, Carol F. AND Ruth N. Bolton(1987), "An Experimental Investigation of Customer Reactions to Service Failure and Recovery Encounter," Journal of Marketing, 51(April), 73-80.

Tax, Stephen S. and Stephen W. Brown(1998), "Recovering and Learning From Service Failure," Sloan Management Review, Vol. 40(1), 75-88.

Stephen W. Brown, and Murali Chandrashekaran(1998), "Customer Evaluation of Service Complaint Experiences: Implications for Relationship Marketing," Journal of Marketing, Vol. 62(April), 60-76.

Winsted, Kathryn Frazer(1999), "Evaluating Service Encounters: A Cross-Culture and Cross-Industry Exploration," Journal of Marketing Theory and Practice, Spring, pp.106-123. 